\title{
Application effect of single balloon catheters in labor induction of pregnant women in late-term pregnancy and their influences on stress and inflammatory responses
}

\author{
YUN CHAI $^{1 *}$, MIAOMIAO QU ${ }^{1 *}$ and MENG JIN ${ }^{2}$ \\ Departments of ${ }^{1}$ Obstetrics and ${ }^{2}$ Gastrointestinal Surgery, \\ The Affiliated Hospital of Jining Medical University, Jining, Shandong 272100, P.R. China
}

Received August 8, 2017; Accepted January 2, 2018

DOI: $10.3892 / \mathrm{etm} .2018 .5767$

\begin{abstract}
This study was designed to evaluate the application effect of single balloon catheters and dinoprostone on promoting cervical ripening of pregnant women in late-term pregnancy and their influences on stress and inflammatory responses. A total of 160 pregnant women with indications of labor induction were included and randomly divided into the control $(n=80)$ and observation $(n=80)$ groups. Patients in the control group received labor induction by administration of dinoprostone at the vaginal vault, while those in the observation group received labor induction by domestic single balloon catheters. Cervical ripening (Bishop score), means of pregnancy, the total stage of labor, maternal and child complications, and Apgar scores of newborn infants at $1 \mathrm{~min}$ after delivery between the two groups were compared. At the prenatal and postpartum 12, 24 and $48 \mathrm{~h}$, the levels of cortisol (COR), norepinephrine (NE) and $\beta$-endorphin $(\beta$-EP), were detected using radioimmunoassay, and those of C-reactive protein (CRP), interleukin-6 (IL-6) and tumor necrosis factor- $\alpha$ (TNF- $\alpha$ ), were measured using enzyme-linked immunosorbent assay (ELISA). Cervical Bishop scores in the two groups after intervention were significantly higher than those before intervention, and the score of the observation group was significantly higher than that of the control group. The difference was statistically significant $(\mathrm{P}<0.05)$. In the observation group, the total stage of labor was significantly shortened, the Apgar score of the newborn infant at 1 min after delivery was increased compared with those in the control group, and the differences were statistically significant $(\mathrm{P}<0.05)$. The delivery rate of cesarean section in the observation group was lower than that in the control group, the overall
\end{abstract}

Correspondence to: Dr Miaomiao Qu, Department of Obstetrics, The Affiliated Hospital of Jining Medical University, 89 Guhuai Road, Rencheng, Jining, Shandong 272100, P.R. China

E-mail: qu47cd@163.com

*Contributed equally

Key words: single balloon catheter, dinoprostone, cervical ripening, stress response, inflammatory response incidence rate of perinatal complications was decreased, and the differences were statistically significant $(\mathrm{P}<0.05)$. The levels of stress and inflammatory response markers at $12 \mathrm{~h}$ after delivery in the two groups reached the peak, and then declined $(\mathrm{P}<0.05)$. The levels of stress and inflammatory response markers at each time-point after delivery in the observation group were significantly lower than those in the control group, and the difference was statistically significant $(\mathrm{P}<0.05)$. The results showed that the single balloon catheter promotes cervical ripening, improves pregnancy outcomes and reduces the stress and inflammatory responses of pregnant women in late-term pregnancy, and is better than dinoprostone and has better application and promotion values.

\section{Introduction}

Delayed pregnancy, pregnancy complications, oligohydramnion, and placental dysfunction are common clinical indications of labor induction (1). Cervical ripening is an important indicator of timing labor induction.

Methods promoting cervical ripening include drugs such as oxytocin and prostaglandin preparations and mechanical methods such as water sac. Dinoprostone is a kind of prostaglandin $\mathrm{E}_{2}$ preparation, which should be locally applied and can be slowly and continuously released, and it has been clinically proven safe and effective (2). The disadvantages include that it easily causes excessive uterine stimulation and frequent uterine contractions, thus increasing the probabilities of fetal distress in the uterus and amniotic fluid contamination (3). The double balloon catheter (Cook) is widely applied to promote cervical ripening, but it is relatively more expensive (4). The main working principle of the domestic single balloon catheter (disposable balloon cervical dilator) is that balloon stresses in the catheter and cervix stimulate the cervical canal such that the synthesis of local cervix is accelerated and endogenous prostaglandins are released, thus promoting cervical softening and ripening (5).

Labor induction in late-term pregnancy can significantly increase the body's stress and inflammatory responses, and the mechanical operation of a single balloon catheter or dinoprostone chemical reaction can further exacerbate the body's stress and inflammatory responses, thus affecting the outcome of perinatal maternal pregnancy to a certain degree. 
This study aimed to evaluate the application effect of a single balloon catheter and dinoprostone on cervical ripening in pregnant women in late-term pregnancy and their influences on stress and inflammatory responses.

\section{Patients and methods}

Data from patients. A total of 160 pregnant women diagnosed with late-term pregnancy in Affiliated Hospital of Jining Medical University (Shandong, China) from January, 2016 to May, 2017, were continuously selected. Inclusion criteria for the study were: i) Patients with indications of labor induction but without history of cervical surgery as well as internal and surgical complications. ii) Patients with cervical Bishop score $\leq 6$ points and with responses in the test without stress. iii) Patients who participated in this research, signed the informed consent and had complete clinical data. Exclusion criteria for the study included patients who suffered from premature ruptures of membranes, vaginal infections, placenta previa or other abnormal pregnancies. The study was approved by the Ethics Committee of The Affiliated Hospital of Jining Medical University.

According to the order of admission, the random number method was used to divide the patients into the control group $(n=80)$ and the observation group $(n=80)$. The baseline data of patients in the two groups were comparable (Table I).

Research methods. The research was completed by the same surgery, midwifery and nursing teams. Patients in the control group received the labor induction by administration of dinoprostone [dinoprostone suppositories, 10 mg, H20090484; Controlled Therapeutics (Scotland) Ltd., Glasgow, Scotland] at the vaginal vault. Specifically, the bladder lithotomy position of pregnant women was disinfected, and dinoprostone was inserted into the vaginal vault. The pregnant women were horizontally laid at $90^{\circ}$ and rested in a bed for $30 \mathrm{~min}$. The Bishop method was used to assess cervical ripening. The emergence of labor, rupture of membranes, rigid and intense uterine contraction, fetal distress in uterus, nausea and vomiting of pregnant women and other reactions indicated that there was a need to immediately remove the drug. If the cervix was not ripened $24 \mathrm{~h}$ after dinoprostone was inserted, intravenous dropping of oxytocin (1 ml: 5 units; National Medicine Permission no. H31020862; Shanghai Pharma No. 1 Biochemical and Pharmaceutical Co., Ltd., Shanghai, China) could be combined. Patients with regular uterine received a contraction response test to determine changes in the fetal heart rate. As long as there was a regular uterine contraction, drugs were discontinued, regardless of the state of the cervix.

Patients in the observation group received labor induction by domestic single balloon catheters (Jiangsu Aiyuan Medical Technology Corp., Jiangsu, China). The lithotomy position was disinfected, the cervix was exposed by bivalve speculum, and the balloon catheter was inserted into the cervical canal to the depth of approximately $10 \mathrm{~cm}$ using oval forceps without teeth. Sterile saline $(150 \mathrm{ml})$ was added using a syringe, and the end of catheter was pasted with anti-allergy adhesive plasters. Pregnant women were free to move; balloons came out on their own after the natural labor, or were removed $12 \mathrm{~h}$ after the insertion. Finally, the Bishop score was assessed.
Observation indicators. Cervical ripening (Bishop score), means of pregnancy, the total stage of labor, maternal and child complications, and Apgar scores of newborn infants at $1 \mathrm{~min}$ after delivery in the two groups were compared, in which the Bishop score was graded according to the following parameters: 0 point for the opening size of the cervix equal to $0 \mathrm{~cm}, 1$ point for $1-2 \mathrm{~cm}, 2$ points for $3-4 \mathrm{~cm}$ and 3 points for $5-6 \mathrm{~cm}$; 0 point for $0-30 \%$ degraded cervical canals, 1 point for $40-50 \%, 2$ points for $60-70 \%$ and 3 points for $80-100 \%$; 0 point for the station of presentation part being $-3,1$ point for $-2,2$ points for $-1-0$ and 3 points for $+1-+2$; 0 point for the cervical hardness being hard, 1 point for medium-hard and 2 points for soft; 0 point for the orifice of the uterus being the rear, 1 point for central position and 2 points for forepart. The final score was the sum of each score.

The levels of cortisol (COR), norepinephrine (NE) and $\beta$-endorphin $(\beta$-EP) were measured by radioimmunoassay at prenatal and postpartum 12, 24 and $48 \mathrm{~h}$. The levels of C-reactive protein (CRP), interleukin-6 (IL-6) and tumor necrosis factor- $\alpha$ (TNF- $\alpha$ ) were measured by enzyme-linked immunosorbent assay (ELISA). Radioimmunoassay reagents were purchased from Jiangsu Beyotime Biotechnology Co., Ltd. (Jiangsu, China) and ELISA reagents were purchased from Beijing Zhong Shan Golden Bridge Biological Technology Co., Ltd. (Beijing, China). The detection was performed 3 times according to the procedures in the instructions, and the average value was calculated.

Statistical methods. Statistical analysis was performed using Statistical Product and Service Solutions (SPSS) 20.0 software (SPSS Inc., Chicago, IL, USA). The measurement data were expressed as mean \pm standard deviation. The independent sample t-test was used for intergroup comparisons, and repeated-measures analysis of variance or paired sample t-test (used for comparisons at two different time-points, such as Bishop score) was used for comparisons at different time-points. Enumeration data are represented as case or (\%), and the $\chi^{2}$ test was used for intragroup comparisons. $\mathrm{P}<0.05$ indicated that the difference was statistically significant.

\section{Results}

Cervical Bishop score, the total stage of labor and Apgar scores of newborn infants at 1 min after delivery. Cervical Bishop scores in the two groups after intervention were significantly higher than those before intervention, and the score of the observation group was significantly higher than that of the control group, and the difference was statistically significant $(\mathrm{P}<0.05)$. The total stage of labor of the observation group was significantly shortened, and the Apgar score of the newborn infant at $1 \mathrm{~min}$ after delivery was increased. The differences were statistically significant $(\mathrm{P}<0.05)$ (Table II).

Means of pregnancy and complications. The delivery rate of cesarean section in the observation group was lower than that in the control group, the overall incidence rate of perinatal complications was decreased, and the differences were statistically significant $(\mathrm{P}<0.05)$ (Table III).

Comparison of stress responses. The levels of stress response markers at $12 \mathrm{~h}$ after delivery in the two groups reached the 
Table I. Comparison of baseline data of patients in the two groups.

\begin{tabular}{|c|c|c|c|c|}
\hline Group & Control group $(\mathrm{n}=80)$ & Observation group $(n=80)$ & $t / \chi^{2}$ & P-value \\
\hline Age (years old) & $25.3 \pm 4.4$ & $24.9 \pm 4.2$ & 0.195 & 0.867 \\
\hline Pregnancy time (week) & $38.5 \pm 2.3$ & $38.9 \pm 2.6$ & 0.098 & 0.946 \\
\hline Reason for labor induction [case (\%)] & & & 1.133 & 0.769 \\
\hline Delayed pregnancy & $9(11.25)$ & $6(7.50)$ & & \\
\hline Pregnancy complications & $34(42.50)$ & $36(45.00)$ & & \\
\hline Oligohydramnion & $30(37.50)$ & $33(41.25)$ & & \\
\hline Placental dysfunction & $7(8.75)$ & $5(6.25)$ & & \\
\hline Bishop score & $3.4 \pm 0.5$ & $3.3 \pm 0.4$ & 0.065 & 0.957 \\
\hline
\end{tabular}

Table II. Comparison of cervical Bishop score, the total stage of labor and Apgar scores of newborn infants at 1 min after delivery.

\begin{tabular}{lccc}
\hline Group & Bishop score & $\begin{array}{c}\text { Total stage of } \\
\text { labor (min) }\end{array}$ & $\begin{array}{c}\text { Apgar } \\
\text { score }\end{array}$ \\
\hline $\begin{array}{l}\text { Control group } \\
\text { (n=80) }\end{array}$ & $10.9 \pm 1.8$ & $460 \pm 80$ & $9.3 \pm 0.4$ \\
$\begin{array}{l}\text { Observation group } \\
\text { (n=80) }\end{array}$ & $12.5 \pm 2.1$ & $430 \pm 75$ & $9.7 \pm 0.5$ \\
t-value & 4.686 & 4.435 & 4.258 \\
P-value & 0.025 & 0.032 & 0.036 \\
\hline
\end{tabular}

peak, and then decreased $(\mathrm{P}<0.05)$. The levels of stress response markers at each time-point after delivery in the observation group were significantly lower than those in the control group, and the difference was statistically significant $(\mathrm{P}<0.05)$ (Fig. 1).

Comparison of inflammatory responses. The levels of inflammatory response markers at $24 \mathrm{~h}$ after delivery in the two groups reached the peak, and then declined $(\mathrm{P}<0.05)$. The levels of inflammatory response markers at each time-point after delivery in the observation group were significantly lower than those in the control group, and the difference was statistically significant $(\mathrm{P}<0.05)$ (Fig. 2).

\section{Discussion}

The study results showed that cervical ripening of the observation group was significantly improved, the total stage of labor was significantly shortened, the Apgar score of the newborn infant at $1 \mathrm{~min}$ after delivery, and the delivery rate of cesarean section and the incidence rate of perinatal complications were decreased in the observation group. The levels of stress and inflammatory responses at 12, 24 and $48 \mathrm{~h}$ after delivery in the observation group were significantly lower than those in the control group. Therefore, we believe that the single balloon catheter promotes cervical ripening, improves pregnancy outcomes and reduces stress and inflammatory responses in pregnant women in late-term pregnancy, and is better than dinoprostone and has better application and promotion values.

Previous findings (6-8) have confirmed that the single balloon catheter produces mild mechanical expansion by taking advantage of water sacs, stimulates endogenous prostaglandin secretion, promotes cervical dilatation, stimulates the release of oxytocins from local plexus of the cervix, assists the expansion of the cervix and promotes the synthesis of cervical tissue collagen and ripening. The single balloon catheter significantly improves the comfort level of pregnant women, and can also directly participate in the active stage, thus shortening the total stage of labor and reducing the pain of delivery. The balloon catheter is not restricted after insertion; thus, there is no need for special observation. If abnormalities appear, it can be easily removed at any time. Drugs are not required in the total stage, and the catheter is easily accepted. It also shortens the hospital stay and reduces hospital costs. Single balloon catheter may cause relatively weaker cervical contraction, which does not affect the rest, and its stage of labor is basically consistent with that of normal labor. It has been reported that single balloon catheter can cause reproductive tract infection after insertion; thus, strict aseptic operation is imperative (9). A recent study has confirmed that the effect of cervical single balloon expansion in promoting cervical ripening is relatively better, and

Table III. Comparisons of means of pregnancy and the incidence rate of complications [case (\%)].

\begin{tabular}{lcccccc}
\hline Group & $\begin{array}{c}\text { Cesarean } \\
\text { section }\end{array}$ & $\begin{array}{c}\text { Postpartum } \\
\text { hemorrhage }\end{array}$ & $\begin{array}{c}\text { Precipitate } \\
\text { labor }\end{array}$ & $\begin{array}{c}\text { Abnormal fetal } \\
\text { heart rate }\end{array}$ & $\begin{array}{c}\text { Amniotic fluid } \\
\text { contamination }\end{array}$ & $\begin{array}{c}\text { Neonatal } \\
\text { asphyxia }\end{array}$ \\
complication
\end{tabular}



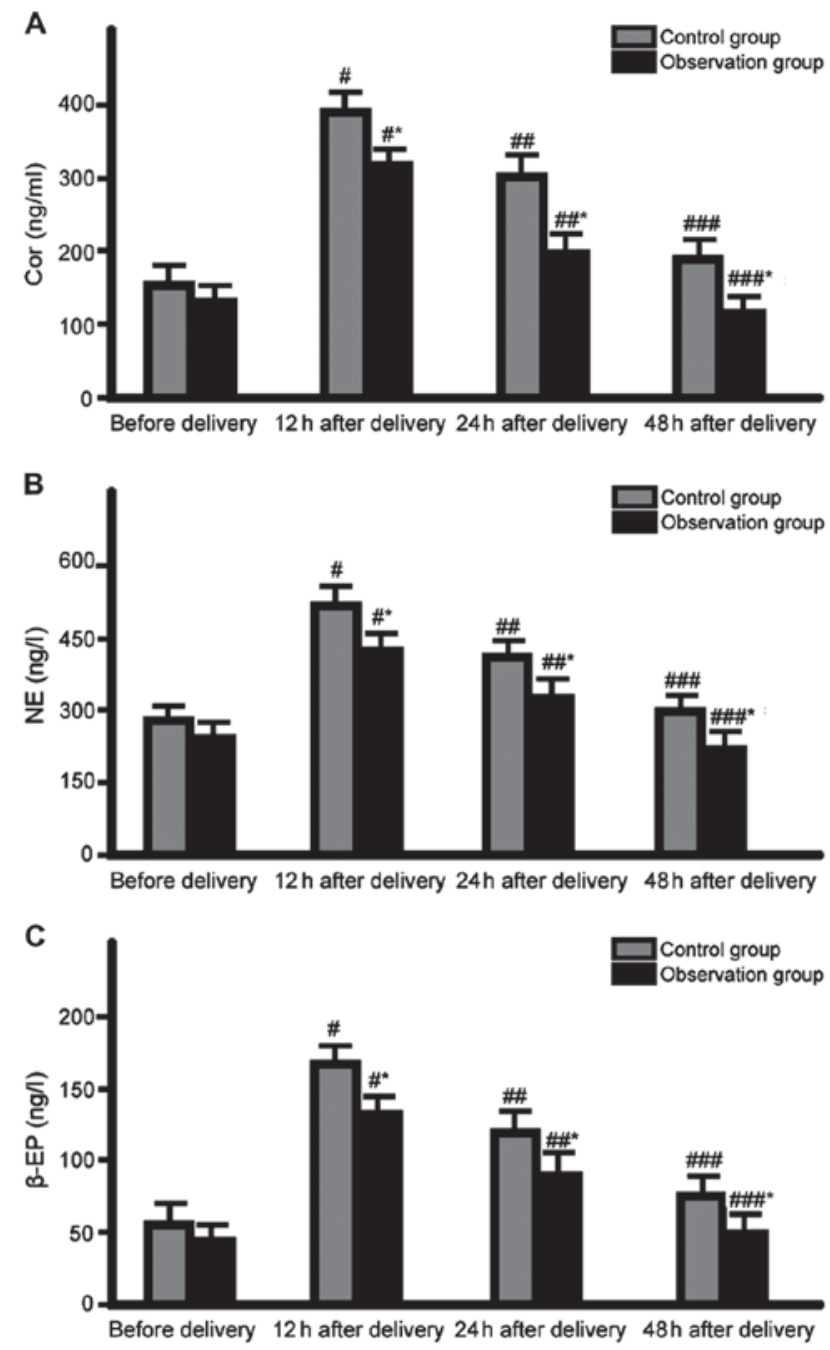

Figure 1. Comparisons of the levels of stress response markers at different time-points between the two groups. (A) The levels of stress response markers at $12 \mathrm{~h}$ after delivery in the control and observation groups are significantly higher than those before delivery $\left({ }^{\#} \mathrm{P}<0.05\right)$. (B) The levels of stress response markers at $24 \mathrm{~h}$ after delivery in the control and observation groups are significantly lower than those at $12 \mathrm{~h}$ after delivery $\left.{ }^{\# \#} \mathrm{P}<0.05\right)$. (C) The levels of stress response markers at $48 \mathrm{~h}$ after delivery in the control and observation groups are significantly lower than those at $24 \mathrm{~h}$ after delivery $\left({ }^{\# \# \#} \mathrm{P}<0.05\right)$. The levels of stress response markers at 12,24 and $48 \mathrm{~h}$ after delivery in the observation group are significantly lower than those in the control group $(" \mathrm{P}<0.05)$.

it can effectively shorten the stage of labor and improve the natural delivery rate with high safety (10). Cervical expansion of a single balloon catheter has a higher natural labor rate and lower delivery rate of cesarean section than that of the double balloon catheter, rendering the former more suitable for clinically promoting cervical ripening (11).

Both cesarean section and vaginal delivery are traumatic stress response sources, which lead to abnormal excitement of the maternal hypothalamus-pituitary-adrenal axis, secretion of a large number of COR, NE and $\beta$-EP, regulate the body stress response and participate in energy metabolism, body temperature regulation and other physiological processes $(12,13)$. COR, $\mathrm{NE}$ and $\beta$-EP are important indicators of body stress responses with high sensitivity (12). The stress response not only improves maternal delivery power, but also reduces postpartum immunity, which is an important reason for puerperal infection and post-
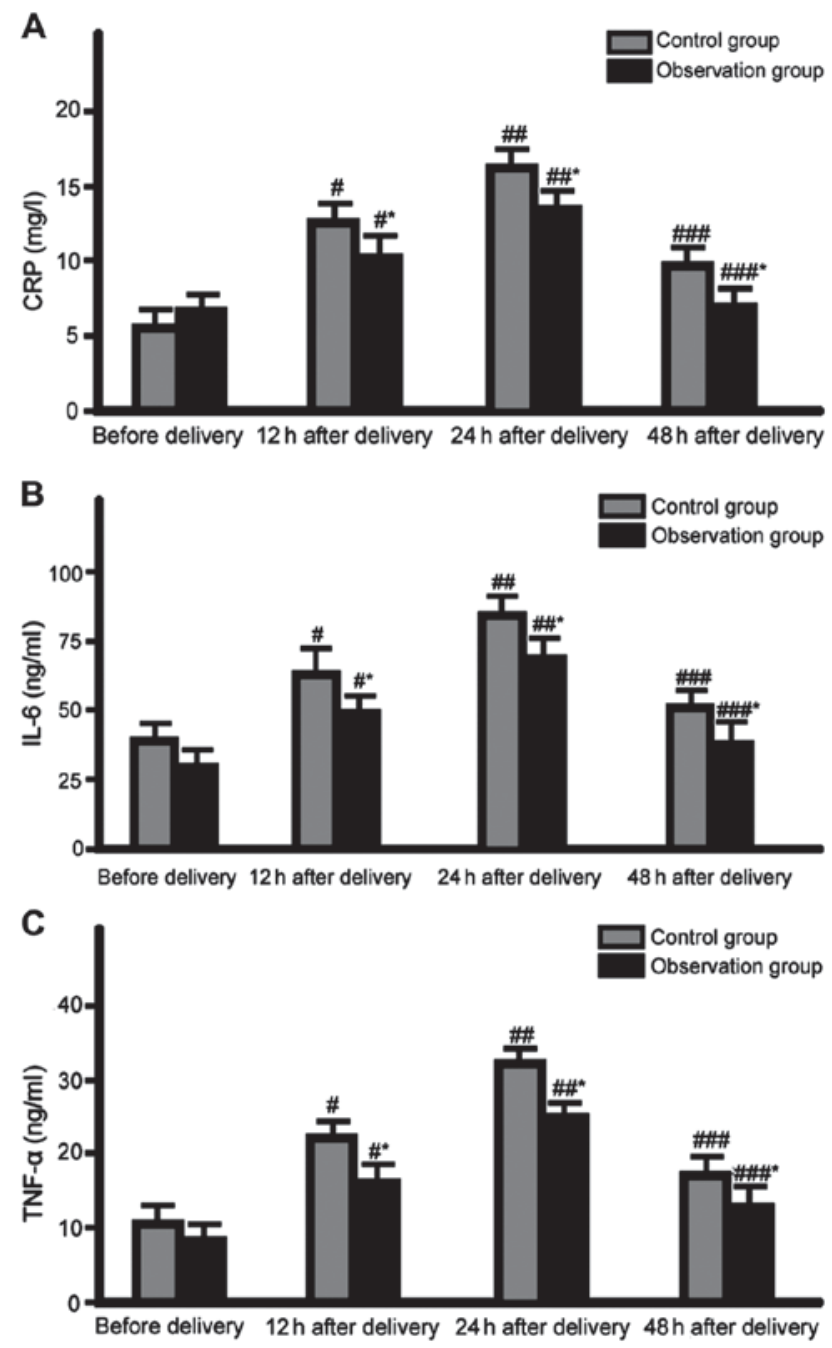

Figure 2. Comparisons of the levels of inflammatory response markers at different time-points between the two groups. (A) The levels of inflammatory response markers at $12 \mathrm{~h}$ after delivery in the control and observation groups are significantly higher than those before delivery ( $\left.{ }^{\#} \mathrm{P}<0.05\right)$. (B) The levels of inflammatory response markers at $24 \mathrm{~h}$ after delivery in the control and observation groups are significantly higher than those at $12 \mathrm{~h}$ after delivery $\left({ }^{\# \#} \mathrm{P}<0.05\right)$. (C) The levels of inflammatory response markers at $48 \mathrm{~h}$ after delivery in the control and observation groups are significantly lower than those at $24 \mathrm{~h}$ after delivery $\left({ }^{\# \# \#} \mathrm{P}<0.05\right)$. The levels of inflammatory response markers at 12, 24 and $48 \mathrm{~h}$ after delivery in the observation group are significantly lower than those in the control group $\left({ }^{*} \mathrm{P}<0.05\right)$.

partum hemorrhage (13). At the same time, the maternal stress response is maintained at peak level, which is also an important risk factor for postpartum anxiety and depression (14). The peak levels of these indicators appear at postpartum $12 \mathrm{~h}$, which is consistent with the time of the peak level of postpartum complications, suggesting that stress responses play important roles in postpartum complications. Inflammatory responses exist in the entire process of delivery. CRP is a very sensitive indicator reflecting the level of inflammation in the body, which can be rapidly increased in the early stage, and its increased degree and duration are often closely associated with disease severity and clinical prognosis (15). IL-6 is a key molecule for triggering and promoting the cascade reaction of inflammation, a chemotactic mediator of other inflammatory cells and a proinflammatory factor of other inflammatory factors (16). TNF- $\alpha$ is an inflammatory factor for regulating nuclear transcription by the body. 
Extracellular signals activate TNF- $\alpha$ activity, and then transfer it into the nucleus, mediate multiple signal transduction pathways and affect the downstream target gene transcription and target protein translation process to play corresponding cytological roles (17). The peak level of inflammatory responses appears at postpartum $24 \mathrm{~h}$, suggesting that inflammatory responses may be closely related to stress responses, and stress responses may be driving powers of the persistent existence of inflammatory responses (18).

In conclusion, the effect of a single balloon catheter on promoting cervical ripening in the labor induction of pregnant women in late-term pregnancy is more exact with high safety. The deficiency of the study is that the sample size is small. Consequently, clinical randomized controlled trials with a larger size of samples are required for verification.

\section{Acknowledgements}

Not applicable.

\section{Funding}

No funding was received.

\section{Availability of data and materials}

The datasets used and/or analyzed during the current study are available from the corresponding author on reasonable request.

\section{Authors' contributions}

YC analyzed and interpreted the patient data, and approved the final manuscript. MQ conceived and designed the study. MQ and MJ were responsible for the data collection. MJ drafted and revised the manuscript for important intellectual content. All authors read and approved the final manuscript.

\section{Ethics approval and consent to participate}

The study was approved by the Ethics Committee of The Affiliated Hospital of Jining Medical University. Patients who participated in this research, signed the informed consent and had complete clinical data.

\section{Consent for publication}

Not applicable.

\section{Competing interests}

The authors declare that they have no competing interests.

\section{References}

1. Bakker R, Pierce S and Myers D: The role of prostaglandins E1 and $\mathrm{E} 2$, dinoprostone, and misoprostol in cervical ripening and the induction of labor: A mechanistic approach. Arch Gynecol Obstet 296: 167-179, 2017.

2. Kim YM, Park JY, Sung JH, Choi SJ, Oh SY, Roh CR and Kim JH: Predicting factors for success of vaginal delivery in preterm induction with prostaglandin $\mathrm{E}_{2}$. Obstet Gynecol Sci 60: 163-169, 2017.
3. Hiersch L, Borovich A, Gabbay-Benziv R, Maimon-Cohen M Aviram A, Yogev Y and Ashwal E: Can we predict successful cervical ripening with prostaglandin $\mathrm{E}_{2}$ vaginal inserts? Arch Gynecol Obstet 295: 343-349, 2017.

4. Sayed Ahmed WA, Ibrahim ZM, Ashor OE, Mohamed ML, Ahmed MR and Elshahat AM: Use of the Foley catheter versus a double balloon cervical ripening catheter in pre-induction cervical ripening in postdate primigravidae. J Obstet Gynaecol Res 42: 1489-1494, 2016.

5. Kehl S, Weiss C and Rath W: Balloon catheters for induction of labor at term after previous cesarean section: A systematic review. Eur J Obstet Gynecol Reprod Biol 204: 44-50, 2016.

6. Salim R, Zafran N, Nachum Z, Garmi G, Kraiem N and Shalev E: Single-balloon compared with double-balloon catheters for induction of labor: A randomized controlled trial. Obstet Gynecol 118: 79-86, 2011.

7. Alfirevic Z, Keeney E, Dowswell T, Welton NJ, Medley N, Dias S, Jones LV, Gyte G and Caldwell DM: Which method is best for the induction of labour? A systematic review, network meta-analysis and cost-effectiveness analysis. Health Technol Assess 20: 1-584, 2016.

8. Jozwiak M, Bloemenkamp KW, Kelly AJ, Mol BW, Irion O and Boulvain M: Mechanical methods for induction of labour. Cochrane Database Syst Rev: Mar 14, 2012 (Epub ahead of print). doi: 10.1002/14651858.CD001233.pub2.

9. Husain S, Husain S and Izhar R: Oral misoprostol alone versus oral misoprostol and Foley's catheter for induction of labor: A randomized controlled trial. J Obstet Gynaecol Res 43: 1270-1277, 2017.

10. Policiano C, Pimenta M, Martins D and Clode N: Efficacy and safety of foley catheter balloon for cervix priming in term pregnancy. Acta Med Port 30: 281-284, 2017.

11. Duro Gómez J, Garrido Oyarzún MF, Rodríguez Marín AB, de la Torre González AJ, Arjona Berral JE and Castelo-Branco C: Vaginal misoprostol and cervical ripening balloon for induction of labor in late-term pregnancies. J Obstet Gynaecol Res 43: 87-91, 2017

12. Vrachnis N, Malamas FM, Sifakis S, Tsikouras $P$ and Iliodromiti Z: Immune aspects and myometrial actions of progesterone and CRH in labor. Clin Dev Immunol 2012: 937618, 2012.

13. Li YY, Yin ZY, Li S, Xu H, Zhang XP, Cheng H, Du L, Zhou XY and Zhang B: Comparison of transvaginal surgery and methotrexate/mifepristone-combined transcervical resection in the treatment of cesarean scar pregnancy. Eur Rev Med Pharmacol Sci 21: 2957-2963, 2017.

14. Florio P, Romero R, Chaiworapongsa T, Kusanovic JP, Torricelli M, Lowry PJ and Petraglia F: Amniotic fluid and umbilical cord plasma corticotropin-releasing factor (CRF), CRF-binding protein, adrenocorticotropin, and cortisol concentrations in intraamniotic infection and inflammation at term. J Clin Endocrinol Metab 93: 3604-3609, 2008.

15. Jagielska I, Kazdepka-Ziemińska A, Janicki R, Fórmaniak J, Walentowicz-Sadłecka M and Grabiec M: Evaluation of the efficacy and safety of Foley catheter pre-induction of labor. Ginekol Pol 84: 180-185, 2013 (In Polish).

16. Eleje GU, Ezugwu EC, Eke AC, Eleje LI, Ikechebelu JI, Ezebialu IU, Obiora CC, Nwosu BO, Ezeama CO, Udigwe GO, et al: Accuracy of a combined insulin-like growth factor-binding protein-1/interleukin- 6 test (Premaquick) in predicting delivery in women with threatened preterm labor. J Perinat Med: Feb 25, 2017 (Epub ahead of print). doi: 10.1515/jpm-2016-0339.

17. Castillo-Castrejon M, Meraz-Cruz N, Gomez-Lopez N, Flores-Pliego A, Beltrán-Montoya J, Viveros-Alcaráz $\mathrm{M}$ and Vadillo-Ortega F: Choriodecidual cells from term human pregnancies show distinctive functional properties related to the induction of labor. Am J Reprod Immunol 71: 86-93, 2014.

18. Bollapragada S, Youssef R, Jordan F, Greer I, Norman J and Nelson S: Term labor is associated with a core inflammatory response in human fetal membranes, myometrium, and cervix. Am J Obstet Gynecol 200: 104.e1-104.e11, 2009.

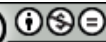

This work is licensed under a Creative Commons Attribution-NonCommercial-NoDerivatives 4.0 International (CC BY-NC-ND 4.0) License. 